\title{
A cfd model of laser cladding: From deposition head to melt pool dynamics
}

Link to publication record in Manchester Research Explorer

\section{Citation for published version (APA):}

Ibarra-Medina, J., Vogel, M., \& Pinkerton, A. J. (2011). A cfd model of laser cladding: From deposition head to melt pool dynamics. In 30th International Congress on Applications of Lasers and Electro-Optics, ICALEO 2011/Int. Congr. Appl. Lasers Electro-Opt., ICALEO (pp. 378-386)

\section{Published in:}

30th International Congress on Applications of Lasers and Electro-Optics, ICALEO 2011|Int. Congr. Appl. Lasers Electro-Opt., ICALEO

\section{Citing this paper}

Please note that where the full-text provided on Manchester Research Explorer is the Author Accepted Manuscript or Proof version this may differ from the final Published version. If citing, it is advised that you check and use the publisher's definitive version.

\section{General rights}

Copyright and moral rights for the publications made accessible in the Research Explorer are retained by the authors and/or other copyright owners and it is a condition of accessing publications that users recognise and abide by the legal requirements associated with these rights.

\section{Takedown policy}

If you believe that this document breaches copyright please refer to the University of Manchester's Takedown Procedures [http://man.ac.uk/04Y6Bo] or contact uml.scholarlycommunications@manchester.ac.uk providing relevant details, so we can investigate your claim.

\section{OPEN ACCESS}




\title{
A CFD MODEL OF LASER CLADDING: FROM DEPOSITION HEAD TO MELT POOL DYNAMICS
}

\author{
Paper \# 708
}

\author{
Juansethi Ibarra-Medina*, Michael Vogel, Andrew J Pinkerton \\ Manufacturing and Management Group, School of Mechanical, Aerospace and Civil Engineering, \\ The University of Manchester, Sackville Street, Manchester M13 9PL, United Kingdom
}

\begin{abstract}
The laser metal deposition process continues to receive attention from researchers and industry due to its unique capabilities in applications such as surface coating or rapid manufacture. The development of numerical models has proven useful for improving the process. However, most models have focused on analyzing individual stages of the deposition process and have required the introduction of a number of assumptions at their limits. This paper describes a complete CFD model that, starting from particles in the deposition head, simulates all interactions that govern the dynamics of a deposition melt pool. Individual phenomena that are included in the gasphase stage of the model include the ricocheting of particles within the head, the flow of powder particles, their interaction with the laser and powder catchment/bouncing. Phenomena in the liquid phase (melt pool) stage of the model include particle enthalpy effects, buoyancy, temperature-dependant material properties and Marangoni forces. The model is demonstrated using the actual geometry and gas flows found in a typical coaxial nozzle. The method, using a single technique to capture all phenomena, allows simulation of the melt pool dynamics from input parameters in a single model.
\end{abstract}

\section{Introduction}

Laser metal deposition (LMD) is a free-form manufacturing technology that is used in a variety of applications such as surface coating, repair of wornout or damaged high-value components and rapid manufacture of medical components. Despite the advantages and usefulness of the technology, its reliability and accuracy are still limited. The quality of the deposited geometries is sensitive to changes in several parameters involved in the process. Traditionally, the selection of optimal processing parameters has been achieved either by experimental approaches of trial and error, or by the use of control systems for real-time tuning of the laser beam [1,2]. These systems are complex and expensive, and more importantly, their aim is to correct the parameters during processing rather than pre-selecting the optimum values based on a rigorous procedure of prediction, which could be a more cost-effective approach. Modeling can be a good tool for predicting the process behavior and hence selecting better processing parameters. A rather wide number of researchers have developed different models capable of analyzing different aspects of the deposition process. A revision of the literature can show that the traditional approach has been to segment the deposition process into individual sections, and model them as separate blocks from the remaining of the elements of the process.

One of the most extended practices has been to detach the powder stream analysis from the melt pool analysis. Most previous works on powder stream modeling have not dealt with the interaction of powder particles with the substrate or the melt pool. Lin [3] used the FLUENT code to develop one of the early models of the free-flowing powder stream, which treated the gas as a diluted phase within the gas flow and did not account for particle collisions with the nozzle or the substrate. Pinkerton and Li [4] presented an analytical model of the powder stream using the geometry of the nozzle as the basis for predicting powder focus and powder distribution. Some effects were not considered such as particle drag or loss of momentum. Yang [5] later developed a similar approach but the velocities of the powder particles were calculated taking the properties of the surrounding assistive gas into account.

Pan et al $[6,7]$ numerically modeled the effects of particle wall collision and irregularities in powder shape using an Euler-Lagrange approach to realistically represent the powder. However, the gasparticle coupling was made only inside the nozzle cavities, and the presence of the substrate was neglected. On the other hand, Toyserkani et al. [8] modeled the trajectory of a single particle being deflected by the substrate, but the assistive gas and the powder particle were assumed to have equal 
velocities, and collisions inside the nozzle walls were neglected.

Subsequent models also included the in-flight heating of the powder stream before reaching the melt pool. Liu and Lin [9] modeled the heating of a single spherical particle irradiated by a defocused laser beam. Diniz Neto [10] and Huang et al. [11, 12] studied the interactions of a laser beam and a powder stream produced by a lateral nozzle, numerically and analytically respectively. They neglected the effects of gas acceleration inside the nozzle as well as particle collision, and for the latter case, the powder particles were assumed to have constant velocities at any location. Pinkerton [13] analytically modeled the powder-laser interactions with a special focus on the phenomena of laser beam attenuation. Wen et al. [14] used the FLUENT code to model the powder stream heating, but similar to the majority of previous works, the presence of a substrate was neglected. He et al. [15] looked at particle impingement patterns using a numerical - analytical decoupled model, in which the effects of substrate melting and real particle deposition were not considered.

On a different aspect, a number of models have studied the processes of clad formation. Unfortunately, very often they have over simplified the treatment of the powder stream. Typically, the stream has been represented with a simple idealized equation. Picasso and Hoadley presented one of the early analytical [16] and Finite Element [17] models in this field, which were developed for a simple twodimensional problem. Toyserkani et al. [18] used the FEMLAB code to model the clad growth by mesh deformation. They used an externally calculated powder stream using analytical simplified expressions in MATLAB. Wang et al. [19] used the technique of element activation-deactivation in SYSWELD to study the melt pool stability in thin wall cladding applications. Their approach was far from reality as the shapes of the clads were simplified into stacked slabs with manually adjusted heights. More crucially, aspects such as powder and melt pool dynamics were not considered.

Zhao et al. [20] used the ANSYS code to simulate stress fields in multi-track deposition. The crosssections of the tracks which are presented in their work have a shape which arguably seems too smooth and idealized for a typical numerical solution. Fallah et al. [21] analyzed the formation of the melt pool using a similar approach, but as Toyserkani et al. and Zhao et al., the powder stream was calculated externally using analytical formulations, and the effects of fluid flow inside the melt pool could not be considered due to the use of FE techniques. Han et al. [22] modeled the flows in the melt pool, and used the level-set method to determine the shape of the clad in a two dimensional domain, which cannot capture flow instabilities across the whole shape of the clad. $\mathrm{He}$ and Mazumder et al. [23] and Qi et al. [24] developed a three dimensional model of the clad growth using the level-set method. They accounted for flows inside the melt pool and Marangoni effects, but assumed a simplified powder stream with an idealized Gaussian distribution, which miscalculates the amount of extra heat added to the melt pool and the location of mass sources for the clad free surface. Wen and Shin [25] have used a similar approach for simulating a LENS system. They developed numerical models of the powder stream and of the clad formation but unfortunately they kept them separate. They ignored the ricocheting of powder particles, laser attenuation effects and used constant properties for the deposited material. Additionally, and similar to Mazumder et al. and Qi et al., the length of the modeled track was very short, roughly $1.5 \mathrm{~mm}$ long, which is arguably an insufficient distance to objectively compare it with an actual experimental deposition. More recently Wen and Shin [26] presented an upgrade of such a model, in which they simulated a case of three overlapped tracks. They kept the same simplifications and produced tracks of less than $0.5 \mathrm{~mm}$ in length. In real applications, where tracks of several millimeters are commonly deposited, it is arguable that these modeled tracks would be of little use. Moreover, a typical experimental deposition requires a few millimeters to exhibit a stable behavior, so their modeled tracks may represent only the initial deposition zone of a clad.

It can be seen that most works up to date have treated different elements the LMD process as detached blocks, and as a consequence some mutually influencing phenomena have not been captured. This can be better achieved when calculations are made within a single fully-coupled domain. This work presents an integrated model of laser deposition, which calculates simultaneously the fundamental phenomena found in the various phases of the process, from those occurring at the deposition head up to those taking place in the melt pool. The model can be used in applications such as lateral or thin wall cladding. Additionally, the model is not excessively demanding in terms of computing resources, thus it is well suited to produce tracks of reasonable lengths that can be compared against experimental samples. 


\section{Model formulation}

Although there are some variations in the setting-up of a nozzle for a deposition equipment, this work is based on the use of a coaxial nozzle, as it is the most widely used configuration. A typical coaxial deposition equipment has the elements shown in Fig. 1.

The powder is supplied by a disk powder feeder at a constant rate using argon gas as the conveying media. The powder flow is then shaped through the nozzle to produce a converging annular stream of powder particles which are focused towards the substrate. A high-energy laser beam is fired on the substrate to create a melt pool. As powder particles arrive at the pool, they are melted and incorporated. The substrate moves relative to the deposition head and a solidified track is formed behind the laser beam.

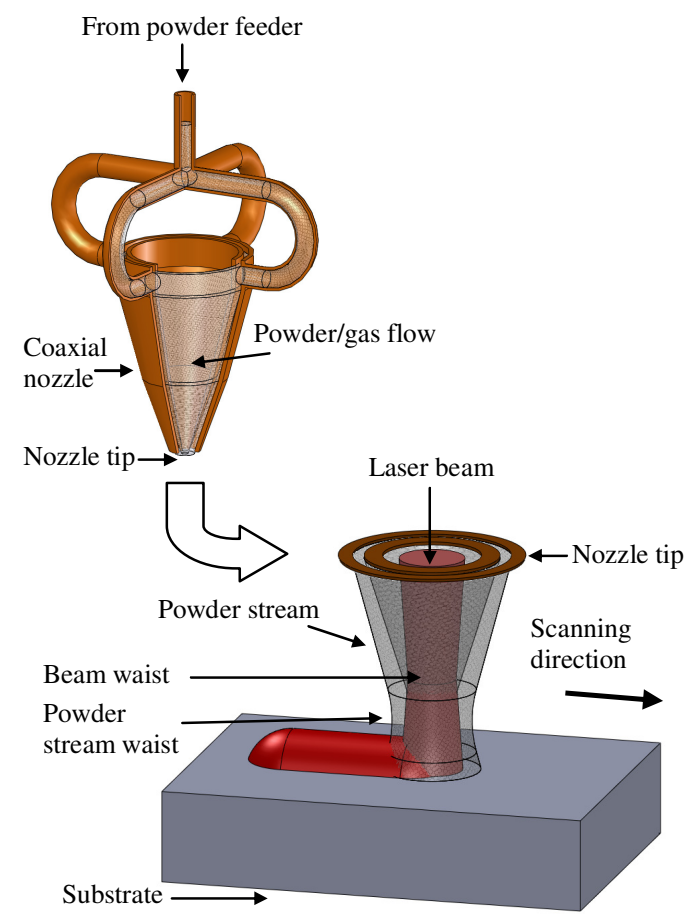

Fig. 1. Schematic of the main elements of a laser deposition set-up.

At each of these stages, the present model simulates the fluid flow and heat transfer phenomena. It starts by calculating the motion of the inert gas which acts as the carrying media for the powder. Its motion is calculated using the following expressions.

Conservation of mass and momentum: $\frac{\partial \rho}{\partial t}+\nabla \cdot\left(\rho_{T} \vec{v}\right)=0$

$\frac{\partial \rho_{T} u}{\partial t}+\nabla\left(\rho_{T} \vec{v} v_{n}\right)=-\nabla p+\nabla\left(\mu \nabla v_{i}\right)$

where $t$ is the time, $v$ is the velocity field, $v_{i}$ represents the velocity in the directions $i=x, y$, and $z ; p$ is the pressure, $\mu$ is the dynamic viscosity, and $\rho_{T}$ is the temperature dependant density respect to a reference density.

Simultaneously, the motion of the powder through the piping of the powder feeder and through the coaxial nozzle is described using the following expression:

$m_{p} \frac{d v_{p}}{d t}=\frac{A_{p} C_{D} \rho_{g}}{2}\left(v_{i}-v_{p}\right)\left|v_{g}-v_{p}\right|+m_{p} g$

where $m_{p}$ is the mass of a particle, $v_{p}$ is the particle velocity field defined by the components $u_{p}, v_{p}$ and $w_{p} ; A_{p}$ is the area of the particle defined as $A_{p}=$ $\pi d_{p}{ }^{2} / 4, C_{D}$ is the drag coefficient, $\rho_{p}$ is the density of the particle and $g$ is the gravity force.

At the same time, the thermal interactions between the powder stream and the laser beam are modeled. Heating of powder particles is treated using a lumped capacitance approach, as discussed in a previous work [27]. Particles intersecting the path of the laser beam are heated according to the following expression:

$$
m_{p} c_{p} \frac{d T_{p}}{d t}=I \eta_{p} \pi r_{p}^{2}-h\left(T_{p}-T_{\infty}\right) 4 \pi r_{p}^{2}-\varepsilon \sigma\left(T_{p}^{4}-T_{\infty}^{4}\right) 4 \pi r_{p}^{2}
$$

where, $c_{p}$ is the specific heat, $T_{p}$ is the temperature of the particle at time $t, \eta_{p}$ is the particle absorption coefficient, $h$ is the heat convection coefficient, $T_{\infty}$ is the temperature of the surrounding gas, $\varepsilon$ is the particle emissivity, $\sigma$ is the Stefan-Boltzman constant, and $I$ is the laser energy intensity.

The modeling of the powder stream continues to the stage where particles impact on the substrate and while this is happening, the heating of the substrate is also calculated using the following expressions:

Conservation of energy:

$\frac{\partial \rho h}{\partial t}+\nabla(\rho \vec{v} h)=\nabla \cdot(k \nabla T)+\frac{\partial p}{\partial t}+\nabla \vec{v}+S_{h}$ 
where $h$ is the enthalpy, $k$ is the thermal conductivity, and $S_{h}$ is an enthalpy source term which takes the form:

$S_{h}=\frac{\eta P}{\pi r_{\omega, \theta, z}^{2}}+S_{h . p o w d e r}-S_{L f}$

in which $\eta$ is the absorption coefficient of the substrate. The first term in the right side takes into account the heat supplied by the laser beam. The second term considers the extra heat from powder particles. The third term considers the effect of latent heat, which is considered by modifying the specific heat capacity at the melting point.

The non-attenuated laser energy incident has a uniform transverse energy distribution, and is described by:

$I=\frac{P}{\pi r_{\omega, \theta, z}^{2}}$

where $I$ is the specific energy from the laser beam, $P$ is the power $r$ is the radial distance to the beam axis and $r_{\omega, \theta, z}$ is the radius of the laser beam respect to a reference waist $\omega$, divergence angle $\theta$, and distance $z$ from the waist location. The actual incident energy at substrate level can be modified by the attenuation of in-flight particles.

The melt pool flow is determined using Equations 1 and 2, while also taking into account important effects such as thermo capillary and Marangoni forces. The free surface motion is analyzed using the Volume of Fluid (VOF) method. This method differs from the traditionally used level-set method, in the manner in which the boundary of the free surface is selected. The level-set method relies on the use of an initial reference line along with values of a vertical function distance in columns of cells, which limits its applicability to cases where the clad grows steadily in the vertical direction, and hence is limited to simple situations where the wetting angle of the clad is less than 90 degrees. On the other hand, the VOF allows the free surface to grow in any direction, thus being able to capture wetting angles larger than 90 degrees. The free surface function is expressed as:

$\frac{\partial F}{\partial t}+u \frac{\partial F}{\partial x}+v \frac{\partial F}{\partial y}+w \frac{\partial F}{\partial z}=0$

where $F$ is a function representing the fractional volume of fluid inside a cell. The value of $F$ can only range between 0 and 1 . It is used here to represent the percentage of the volume of a cell that is occupied by a fluid, which in this work represents the metallic material. A cell with an $F$ value of one, would represent a cell completely filled with the fluid, whereas an $F$ value of zero would represent a cell with no fluid. In this model, the $F$ function is initialized with values of unity for cells representing the geometry of the substrate, and with values of zero for cells representing the gas media above it, such as in Fig 2.

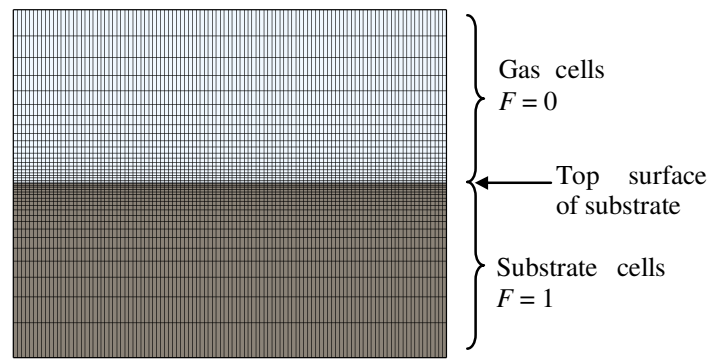

Fig. 2. Initial state of $F$ function for cells where the substrate is defined.

The $F$ function is updated every time step, and is influenced by flows in the melt pool and by mass addition from incoming powder particles. The $F$ function is solved explicitly. A mass source term is added for those cells where powder particles are absorbed in the melt pool.

$$
S_{\text {mass.powder }}=\sum_{i=1}^{n} V_{p . i} \rho
$$

where the right hand side term represents the sum of the mass of all particles found to transfer their mass in a given cell. As mentioned earlier, the location and mass of powder particles is calculated using Equation 3.

\section{Numerical procedure}

The model of the laser cladding process is divided in two sections, as shown in Fig. 3. The first sectionmodel, Fig. 3a, computes the flows of powder and assistive gases through the coaxial nozzle. A revolved non-uniform structured mesh is used, the smallest cell size being $16.93 \mu \mathrm{m}$. The second section, Fig. 3b, represents the substrate base with the zone of gas between it and the nozzle tip. A rectangular non-uniform structured mesh is used. It is refined in the area where the deposition is expected to occur. The first section-model calculates the powder trajectories and velocities through the coaxial nozzle. Data of powder particles at the tip of this model is transferred to the corresponding locations at the uppermost boundary cells of the second section- 
model. The calculation of the powder stream after the nozzle tip continues to be calculated within the second section-model, thus being solved simultaneously and fully integrated to the modeling of the clad growth. Flows inside the melt pool can show an unstable behavior due to the temperaturedriven change of different material properties, as well as the processes of mass addition. Hence, the deposition process is modeled in a transient manner, using constant time steps of 0.002 seconds. This chosen time step is sufficiently small as to avoid the function $F$ exceeding the unity in a single time step. The commercial code CFD-ACE+ is used.
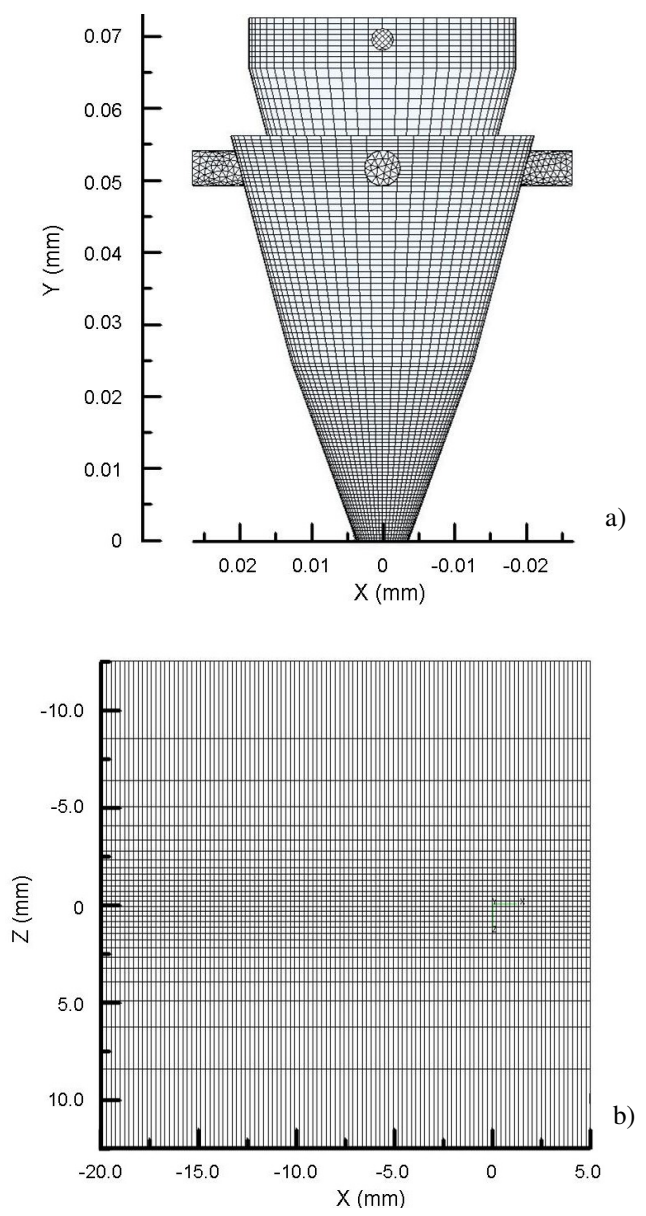

Fig. 3. Representation of the mesh for the sectionmodels. a) Coaxial nozzle. b) Substrate

\section{Results and discussion}

The processing conditions used in this simulation are shown in Table 1. The substrate material is AISI 316L stainless steel, of dimensions $25 \times 25 \times 10 \mathrm{~mm}$. It is located at a standoff distance of $10 \mathrm{~mm}$ below the nozzle tip.
A circular laser beam, with 'top hat' intensity distribution, generated by a diode laser is positioned at the initial coordinates $\mathrm{x}=0 \mathrm{~mm}, \mathrm{y}=-7.5 \mathrm{~mm}, \mathrm{z}$ $=0 \mathrm{~mm}$, using the beam waist as the reference point. Since the waist is located at $2.5 \mathrm{~mm}$ above the substrate, the laser beam is widened at the location of the substrate due to divergence. The scanning direction is in the negative $\mathrm{x}$ direction. The scanning speed is set at $10 \mathrm{~mm} / \mathrm{s}$.

Table 1. Material properties used in the simulation.

\begin{tabular}{|c|c|c|}
\hline Property & Value & Units \\
\hline Melting temperature & 1723.0 & $\mathrm{~K}$ \\
\hline Solid density at $300 \mathrm{~K}$ & 7950.0 & $\mathrm{~kg} / \mathrm{m}^{3}$ \\
\hline Solid density coefficient & -0.5129 & $\mathrm{~kg} / \mathrm{m}^{3} \mathrm{~K}$ \\
\hline Liquid density at $1723 \mathrm{~K}$ & 6881.0 & $\mathrm{~kg} / \mathrm{m}^{3}$ \\
\hline Liquid density coefficient & -0.7697 & $\mathrm{~kg} / \mathrm{m}^{3} \mathrm{~K}$ \\
\hline $\begin{array}{l}\text { Solid thermal conductivity } \\
\text { at } 300 \mathrm{~K}\end{array}$ & 13.4 & $\mathrm{~W} / \mathrm{m} \mathrm{K}$ \\
\hline $\begin{array}{l}\text { Solid thermal conductivity } \\
\text { coefficient }\end{array}$ & 0.0136 & $\mathrm{~W} / \mathrm{m} \mathrm{K}^{2}$ \\
\hline $\begin{array}{c}\text { Liquid thermal } \\
\text { conductivity at } 1723 \mathrm{~K}\end{array}$ & 28.5 & $\mathrm{~W} / \mathrm{m} \mathrm{K}$ \\
\hline $\begin{array}{c}\text { Liquid thermal } \\
\text { conductivity coefficient }\end{array}$ & 0.00886 & $\mathrm{~W} / \mathrm{m} \mathrm{K}^{2}$ \\
\hline Solid specific heat & 470 & $\mathrm{~J} / \mathrm{kg} \mathrm{K}$ \\
\hline $\begin{array}{c}\text { Solid specific heat } \\
\text { coefficient }\end{array}$ & 0.184 & $\mathrm{~J} / \mathrm{kg} \mathrm{K}^{2}$ \\
\hline Liquid specific heat & 830 & $\mathrm{~J} / \mathrm{kg} \mathrm{K}$ \\
\hline Latent heat of fusion & $2.6 \times 105$ & $\mathrm{~J} / \mathrm{kg}$ \\
\hline Liquid viscosity at $1723 \mathrm{~K}$ & 0.0056 & $\mathrm{~Pa} \mathrm{~s}$ \\
\hline $\begin{array}{l}\text { Liquid viscosity } \\
\text { coefficient }\end{array}$ & $-3.72 \times 10-6$ & $\mathrm{~Pa} \mathrm{~s} / \mathrm{K}$ \\
\hline Surface tension coefficient & $-3.9 \times 10-5$ & $\mathrm{~N} / \mathrm{m} \mathrm{K}$ \\
\hline $\begin{array}{l}\text { Solid absorptivity for } \\
\text { infrared beam }\end{array}$ & 0.5 & \\
\hline $\begin{array}{l}\text { Liquid absorptivity for } \\
\text { infrared beam }\end{array}$ & 0.6 & \\
\hline
\end{tabular}

The powder is supplied from a coaxial nozzle at a constant flow of $0.0028 \mathrm{~g} / \mathrm{s}$. Fig. 4 illustrates a sequence of the formation of a clad. Under the conditions used, powder particles emerge from the nozzle having a converging trajectory towards the substrate. They converge at a distance between 8 and $10 \mathrm{~mm}$ below the nozzle tip. The achieved focus of the powder stream, $2 \mathrm{~mm}$, is rather poor. Particles which cross the laser beam are heated rapidly depending on the interaction time. In such a poorly focused powder stream, particles quickly diverge from the waist, and it is common to observe the hottest particles on the outside boundaries. Before the melt pool is formed, powder particles ricochet from the substrate and are lost. The area irradiated by the 
laser beam heats up rapidly. Initially, this process is driven by heat conduction. However, as the material passes to the liquid state, forces of buoyancy and surface tension create strong flows inside the melt pool. These flows enhance heat transfer by convection, thus contributing to the growth of the melt pool, which can extend beyond the area irradiated by the laser beam. The temperature of the melt pool reaches $2072 \mathrm{~K}$. The molten material can flow away from the centre of the pool or towards it, influenced by the surface tension gradient. Powder entering the melt pool is melted and its mass is transferred to the melt pool. The added material is kept on top of the substrate because of the stacking of additional mass on the pool. The inflow of powder depends on the trajectory of individual particles. This inflow is not homogeneously distributed across the melted area. Thus, it is also possible to observe zones of localized motion near the surface of the melt pool, as the newly added material flows to distribute itself across the volume of the pool.
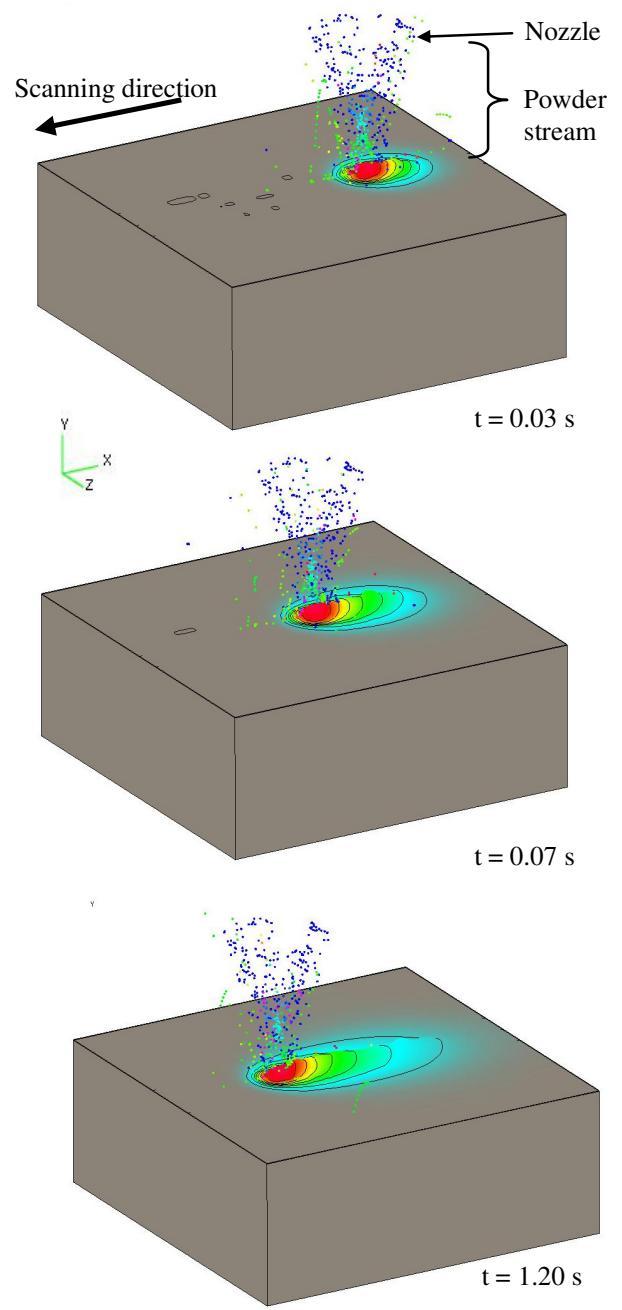

The liquid material tends to follow a sphere-like shape due to the surface tension, but the actual shape is elongated due to the displacement of the laser beam and the cooling at the rear of the pool. Across the longitudinal surface of the clad, it is also possible to observe zones of irregular or fluctuating profile. This can be caused because at some points the strong flows in the melt pool enhance the heat transfer to an extent which temporarily increases the molten region, and more powder can be trapped. This however, stabilizes as the scanning progresses.

A direct comparison is made between the modeled clad and an experimental deposition, using the same materials and conditions. The experimental deposition is made using a Laserline LDL 160-1500 diode laser, coupled to a circular fiber delivery head which delivers a nominal power of $1000 \mathrm{~W}$.
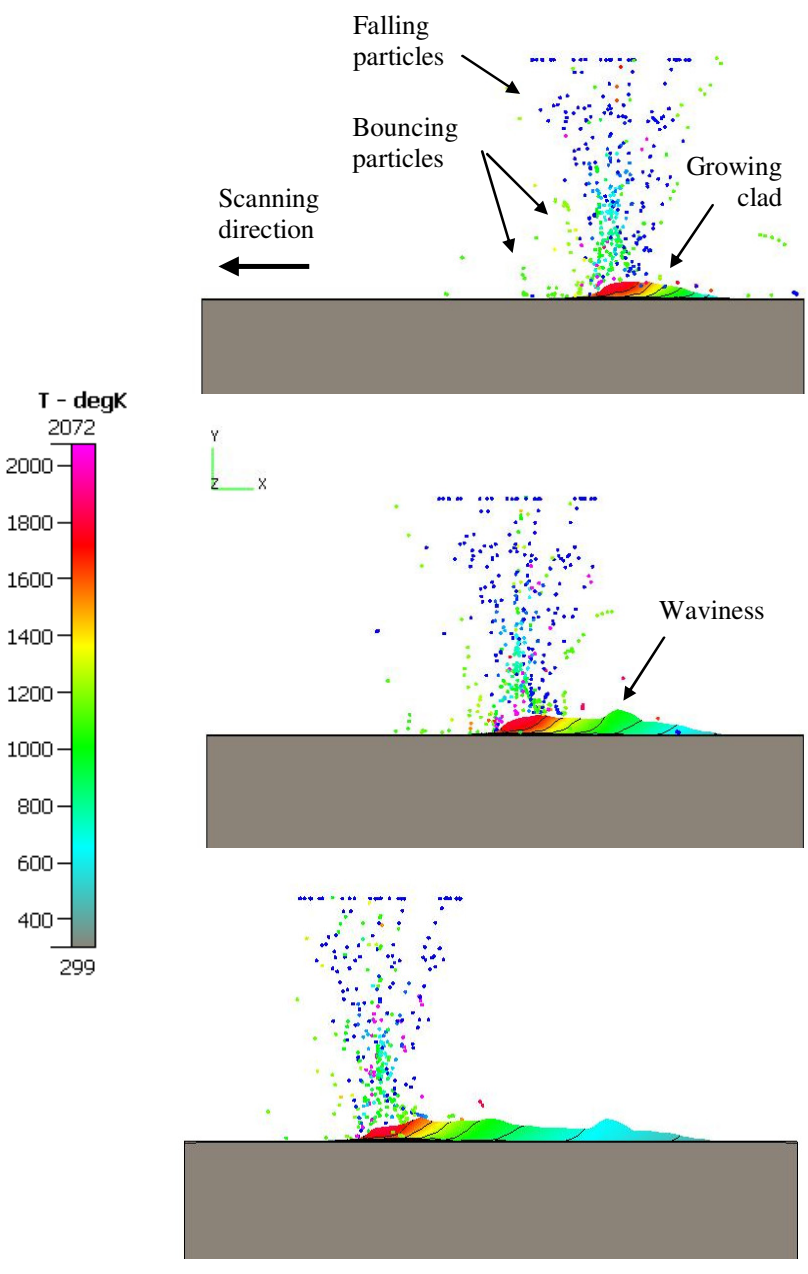

Fig. 4. Sequence of the deposition at different times, isometric and lateral views 
Powder is supplied using a Simatic OP-3 disk powder feeder, at a constant rate of $0.28 \mathrm{~g} / \mathrm{s}$. The powder is focused using a custom-made coaxial nozzle. Motion of the substrate is provided by a 2-axes NC table. Three single-track depositions are made. The samples are cut in the transverse direction at a zone where a stable profile is observed. The transverse profiles are measured and averaged. Similar trends between the modeled and experimental depositions are observed in the growth of the clad, particularly at their start and ending points, as well as in the longitudinal profile. Fig. 5 shows a comparison of the experimental and modeled tracks. Good agreement is observed between the profiles of the experimental and modeled tracks. The heights of the clads show good agreement, whereas the width is overestimated by a percentage of $16 \%$. This could be due to an overestimation of the melt pool size, which in turn may be caused by differences between the material properties used in the simulation and those of the actual substrate and powder materials, particularly the absorption coefficient, which is not accurately known.

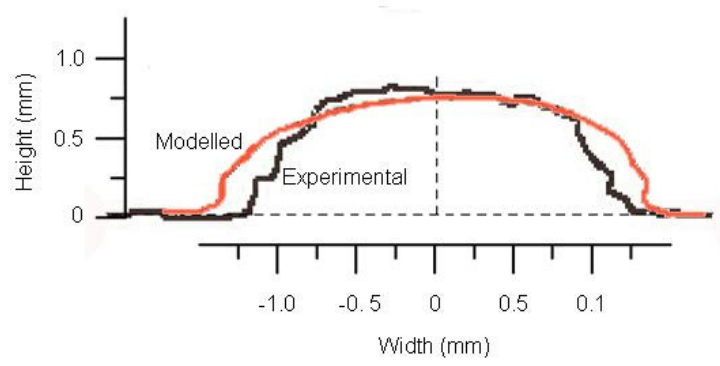

Fig. 5. Profiles of track transversal cross section, modeled and experimental.

Additional capabilities of the model, such as multitrack deposition for thin wall applications or lateral overlapping, are currently being developed. It is worth noting that track geometry is one of multiple possible outputs for the model. Work is currently underway to extract information from the melt pool and use it for predicting other properties of the final deposited part. These capabilities will be presented in a future work.

\section{Conclusions}

A fully coupled model of the laser cladding process has been developed. The model accounts for phenomena of powder motion by gas drag and collisions with nozzle and substrate walls, thermal interactions between the powder stream and laser beam, particle catchment and ricocheting, melt pool formation and melt pool flows, heat transfer from powder to melt pool and mass addition.

Contrary to previous models, the realistic distribution and conditions of the powder stream are solved simultaneously with the melt pool, thus fewer assumptions are made at the interfaces between the different phases of the process.

The volume of fluid method is applied in this work to determine the free surface of the clad. This method could be used for simulating complicated shapes such as those found in clads with high wetting angle or inter-clad porosity.

The model is able to produce clads of realistic shape, both in terms of transverse profile and of length of the clad. Moreover, the present work is demonstrated as able to simulate depositions of the order of several millimeters in length, on a desktop computer, making it relevant for industrial applications.

\section{Acknowledgements}

Juansethi Ibarra-Medina gratefully acknowledges the full support of the Mexican National Council for Science and Technology (CONACYT). This work is also supported by EU FP7 IAPP Agreement 230756 'INLADE'. Thanks are also due to project partners Dr Mustafa Megahed and Dr N'Dri Abou Narcisse, from ESI GmbH.

\section{References}

[1] Mazumder, J., (2000) Crystal ball view of directmetal deposition. JOM. 52-12.

[2] Mazumder, J., D. Dutta, N. Kikuchi, and A. Ghosh, (2000) Closed loop direct metal deposition: art to part. Optics and Lasers in Engineering. 34-4-6.

[3] Lin, J.M., (2000) Numerical simulation of the focused powder streams in coaxial laser cladding. Journal of Materials Processing Technology. 105-1-2.

[4] Pinkerton, A.J. and L. Li, (2004) Modelling powder concentration distribution from a coaxial deposition nozzle for laser-based rapid tooling. Journal of Manufacturing Science and EngineeringTransactions of the Asme. 126-1.

[5] Yang, N., (2009) Concentration model based on movement model of powder flow in coaxial laser cladding. Optics and Laser Technology. 41-1.

[6] Pan, H., R.G. Landers, and F. Liou, (2006) Dynamic modeling of powder delivery systems in 
gravity-fed powder feeders. Journal of Manufacturing Science and Engineering-Transactions of the Asme. 128-1.

[7] Pan, H., T. Sparks, Y.D. Thakar, and F. Liou, (2006) The investigation of gravity-driven metal powder flow in coaxial nozzle for laser-aided direct metal deposition process. Journal of Manufacturing Science and Engineering-Transactions of the Asme. 128-2.

[8] Toyserkani, E., A. Khajepour, and S. Corbin, (2005) Laser cladding, Boca Raton, FL: CRC Press.

[9] Liu, C.Y. and J. Lin, (2003) Thermal processes of a powder particle in coaxial laser cladding. Optics and Laser Technology. 35-2.

[10] Diniz Neto, O. and R. Vilar, (2002) Physicalcomputational model to describe the interaction between a laser beam and a powder jet in laser surface processing. Journal of Laser Applications. 14-1.

[11] Huang, Y.L., G.Y. Liang, J.Y. Su, and J.G. Li, (2005) Interaction between laser beam and powder stream in the process of laser cladding with powder feeding. Modelling and Simulation in Materials Science and Engineering. 13-1.

[12] Huang, Y.L., J. Liu, N.H. Ma, and J.G. Li, (2006) Three-dimensional analytical model on laserpowder interaction during laser cladding. Journal of Laser Applications. 18-1.

[13] Pinkerton, A.J., (2007) An analytical model of beam attenuation and powder heating during coaxial laser direct metal deposition. Journal of Physics DApplied Physics. 40-23.

[14] Wen, S.Y., Y.C. Shin, J.Y. Murthy, and P.E. Sojka, (2009) Modeling of coaxial powder flow for the laser direct deposition process. International Journal of Heat and Mass Transfer. 52-25-26.

[15] He, W., L. Zhang, and P. Hilton. (2009) Modelling and validation of a direct metal deposition nozzle, in 28th International Congress on Applications of Lasers \& Electro-Optics. Orlando, FL, USA: Laser Institue of America.

[16] Picasso, M., C.F. Marsden, J.D. Wagniere, A. Frenk, and M. Rappaz, (1994) A simple but realistic model for laser cladding. Metallurgical and Materials Transactions B-Process Metallurgy and Materials Processing Science. 25-2.
[17] Picasso, M. and A.F.A. Hoadley, (1994) Finite element simulation of laser surface treatments including convection in the melt pool. International Journal of Numerical Methods for Heat and Fluid Flow. 4-1.

[18] Toyserkani, E., A. Khajepour, and S. Corbin, (2004) 3-D finite element modeling of laser cladding by powder injection: effects of laser pulse shaping on the process. Optics and Lasers in Engineering. 41-6.

[19] Wang, L., S. Felicelli, Y. Gooroochurn, P.T. Wang, and M.F. Horstemeyer, (2008) Optimization of the LENS ${ }^{\circledR}$ process for steady molten pool size. Materials Science and Engineering: A. 474-1-2.

[20] Zhao, H.-y., H.-t. Zhang, C.-h. Xu, and X.-q. Yang, (2009) Temperature and stress fields of multitrack laser cladding. Transactions of Nonferrous Metals Society of China. 19-Supplement 2.

[21] Fallah, V., M. Alimardani, S.F. Corbin, and A. Khajepour, (2011) Temporal development of meltpool morphology and clad geometry in laser powder deposition. Computational Materials Science. 50-7.

[22] Han, L., F.W. Liou, and K.M. Phatak, (2004) Modeling of laser cladding with powder injection. Metallurgical and Materials Transactions B-Process Metallurgy and Materials Processing Science. 35-6.

[23] He, X. and J. Mazumder, (2007) Transport phenomena during direct metal deposition. Journal of Applied Physics. 101-5.

[24] Qi, H., J. Mazumder, and H. Ki, (2006) Numerical simulation of heat transfer and fluid flow in coaxial laser cladding process for direct metal deposition. Journal of Applied Physics. 100-2.

[25] Wen, S.Y. and Y.C. Shin, (2010) Modeling of transport phenomena during the coaxial laser direct deposition process. Journal of Applied Physics. 1084.

[26] Wen, S.Y. and Y.C. Shin, (2011) Comprehensive predictive modeling and parametric analysis of multitrack laser deposition processes. Journal of Laser Applications. 23-2.

[27] Ibarra-Medina, J. and A. Pinkerton, (2011) Numerical investigation of powder heating in coaxial laser metal deposition Surface Engineering. 27-6. 


\section{Meet the Author(s)}

Juansethi Ibarra-Medina is currently working at The University of Manchester as a Ph.D student of Mechanical Engineering, in the field of laser processing. He has previously earned a master's degree in mechanical design and a bachelor's degree in manufacturing engineering and has worked as an engineer in different automotive companies. His current interests are laser deposition and modeling of fluid dynamics in laser processes.

Michael Vogel is currently working at The University of Manchester as a Ph.D student of Mechanical Engineering in the field of laser processing. He previously earned a diploma (Dipl.-Ing.) in Mechanical Engineering from University of Karlsruhe, Germany. His current interests are laser deposition and numerical simulations in manufacturing.

Dr. Andrew J Pinkerton is a faculty research fellow at The University of Manchester. He holds a PhD in Laser Material Processing from UMIST and has published over 100 papers in this field. His research interests include laser direct metal deposition, welding, surface modification and modeling of laser processes. 